\title{
Chapter 5 \\ Exploring the Protective Role of Sex Work Social Cohesion in Contexts of Violence and Criminalisation: A Case Study with Gender-Diverse Sex Workers in Jamaica
}

\author{
Carmen H. Logie, Ying Wang, Patrick Lalor, Kandasi Levermore, \\ and Davina Williams
}

\section{Background}

Sex workers experience stigma and marginalisation across global contexts. With claims of sex work being among the oldest professions in the world [1], there is a long history of stigma directed towards sex workers [2-4]. Stigma contributes to the precarious nature of sex work, producing social, legal, and work environments that increase exposure to violence while reducing access to legal support and health care [5-7]. The convergence of stigma and violence targeting sex workers contributes to disparities when it comes to their mental and sexual health. Client violence and stigma have been associated with depression among sex workers [8]. A systematic review examining HIV vulnerabilities among transgender (trans) sex workers noted that the convergence of violence and stigma against sex workers compromises sexual health [5].

Sex work is criminalised in many countries across the world [9, 10]. The criminalisation of sex work presents profound barriers to sex workers when it comes to accessing healthcare services and legal support [7]. Due to a lack of legal protections,

\footnotetext{
C. H. Logie ( $ه)$

Factor-Iwentash Faculty of Social Work, University of Toronto, Toronto, ON, Canada

Women's College Research Institute, Women's College Hospital, Toronto, ON, Canada e-mail: carmen.logie@utoronto.ca

Y. Wang

Factor-Iwentash Faculty of Social Work, University of Toronto, Toronto, ON, Canada

P. Lalor

Sex Work Association of Jamaica, Kingston, Jamaica

Jamaica AIDS Support for Life, Kingston, Jamaica

K. Levermore $\cdot$ D. Williams

Jamaica AIDS Support for Life, Kingston, Jamaica
} 
sex workers may experience violence from clients, community members, police and/ or intimate partners, with little recourse to justice [11]. This may be exacerbated for sexually and gender-diverse sex workers in contexts such as Jamaica, where not only sex work but also same-gender sexual practices are criminalised [12]. Studies from China report high prevalence of gender-based violence among sex workers, with associated harms including physical (e.g. chronic pain and injury), reproductive (e.g. unwanted pregnancy) and mental (e.g. post-traumatic stress disorder and depression) health outcomes [13]. A study from India reported that physical, verbal, and sexual violence from intimate partners and others were associated with suicide attempts and self-harm on the part of sex workers [14]. The convergence of violence and mental health challenges can reduce the ability of sex workers to negotiate safer sex practices, such as condom use [14-16].

Sex workers have identified that community-based empowerment interventions - initiated and led by sex workers — number among effective strategies towards reducing barriers to their health and well-being [17]. These strategies can provide education and peer-support. There is an evidence-base documenting the association between improved health among sex workers and sex worker social cohesion [17, 18]. Social cohesion is a complex concept that emphasises "sense of belonging" among people within a given society or community, and which may be leveraged to reduce violence and challenge injustices, including criminalisation and human rights violations [19]. Within this context of social cohesion, social support and mutual respect can facilitate knowledge sharing and other social norms that work towards promoting health. Social cohesion can also reduce barriers to accessing healthcare services [20].

Social cohesion when it comes to sex work is multifaceted and includes mutual aid and support. Social cohesion among sex workers is associated with increased odds of condom use and reduced HIV acquisition in countries including India [18], Swaziland [17], and Canada [16]. A study in Eswatini (Swaziland) [17] found that social cohesion among sex workers was associated with increased condom use, reduced social discrimination, and reduced police violence [17].

As several studies have reported in China [13, 21], India [14], and Jamaica [15], violence against sex workers contributes to mental health challenges and reduced condom use. Fewer studies have explored associations between social cohesion among sex workers and their mental health outcomes, which is important to examine, considering that social cohesion appears to have mental health benefits among general populations. A cross-national analysis of World Values surveys spanning 69 countries studied the associations between social capital and trust within a country and the health of its citizens [22]. Among some European countries, higher social capital was associated with improved health outcomes [22]. A longitudinal analysis in South Wales, UK [23] examined the correlation between social cohesion in neighbourhoods and individual mental health. They found that neighbourhoods with higher social cohesion were linked with the improved mental health of individuals. It is plausible that social cohesion among sex workers would similarly be associated with improved mental health outcomes in this group. 
This chapter address the knowledge gaps regarding associations between social cohesion among sex workers and improved mental health and reduced exposure to violence. We provide a case example from Jamaica, a salient context within which to examine the experiences of cisgender men and trans women sex workers, who experience both sex work criminalisation and criminalisation of same-gender sexual practices [12]. The objectives of this chapter are to: (1) explore a case study reflecting the lived experiences of a sex worker in Jamaica; (2) examine findings from a community-based study among gender-diverse sex workers in Jamaica (cisgender men and women, and transgender (trans) women) that assesses social cohesion among sex workers and its associations with stigma against sex work, mental health, harassment and arrest by police, and exposure to violence; and (3) discuss implications for activists, researchers, and service providers working with sex workers in diverse global contexts. This chapter begins with the case study, followed by empirical findings from a community-based research project. We end by discussing implications for practice and future research.

\section{Case Study: Human Rights Violations Experienced by a Sex Worker in Jamaica}

The following case study was compiled following in-depth conversations with members of the Sex Worker Association of Jamaica (SWAJ), conducted by chapter author Patrick Lalor of SWAJ. Largely based on the narrative of one person, the overall goal of this case study is to share a snapshot of the life of a sex worker, with a focus on human rights experiences and social cohesion among sex workers. It cannot and does not aim to capture the lived experiences of all sex workers in Jamaica and may only reflect some elements of the realities shared by cisgender women sex workers in this country. The narrative is written in the third person to reflect the retelling of these lived experiences by practitioners and academics.

In the heart of Kingston, Jamaica, in an inner-city community called "Back to", a single mother struggled to support seven children. Her eldest daughter, Maria, ${ }^{1}$ could not regularly attend school as she needed to care for her younger siblings while her mother worked. Maria started doing sex work when she was 18 years old, having dropped out of school when she became pregnant at 16. Although she became pregnant as a minor, despite the fact that sex with minors is an offence under Jamaican law, there were no legal consequences. A decade ago, when she was 20, Maria migrated from Kingston to Montego Bay to advance her sex work career. Over this decade Maria has had three other children, and reports experiences of abuse, legal involvement, rape and other forms of violence.

On a cold dark night in 2011 on the streets of Montego Bay, Maria was at her regular spot sourcing clients when a car pulled up and the driver asked if she was

\footnotetext{
${ }^{1}$ Name changed to a pseudonym to protect privacy.
} 
doing business. After negotiating, she got into the car and the client drove to a remote location and then ordered her to get out. They went into what appeared to be an abandoned building and to her surprise there were three other men there waiting. One of them pulled out a gun and ordered her to remove her clothes. He informed her that if she did not comply, he would kill her. She did as she was ordered, and all four men raped her. She begged them not to kill her and did everything they commanded. After they were finished, one of the men searched her purse, took all of the money she had on her, including payments from two prior clients, and also took her phone. The men all left in the car. Maria was distraught, and in a strange and unknown place. She wandered in the dark until she saw a familiar landmark. She managed to hail a cab with a driver that she was familiar with, and he dropped her home.

Maria confirmed that, even though many sex workers in Jamaica face serious and commonplace incidences of violence and abuse, they never go to the police. She recounted experiences of three of her colleagues: the first, Mary, ${ }^{2}$ went to the police to report being raped and was subsequently arrested for engaging in sex work. Angela ${ }^{3}$ was raped by the police and told if that she tried to report this, she would be arrested, as sex work was illegal. The body of another colleague, Jacky, ${ }^{4}$ was found on a beach after she had left her regular spot with an unknown client. In the midst of this trauma, in 2014, Maria lost custody of two of her children when she was declared an 'unfit mother' by child protective services, after the father of one of her children reported that she was a sex worker. There was no evidence indicating that she was endangering her children or causing them any harm-according to Maria, her children were removed due to the stigma of her being a sex worker. Maria visits her children, who are in state care, monthly but feels deep grief and loss every time she visits, as she is forced to leave them behind.

Maria reported that she had a nervous breakdown in 2015. So much was happening in her life, and she had no one to talk to. She found solace in meeting with fellow sex workers who gather nightly to share stories and frustrations. These meetings often involve alcohol, cigarettes and marijuana while waiting for the next clients. While these regular meetings help to ease the pain of struggles in everyday life, going back to reality is often challenging.

In 2016, a sex work club was raided, and Maria was the only sex worker arrested. A friend of Maria's, Gloria, ${ }^{5}$ was familiar with the Sex Work Association of Jamaica (SWAJ) and contacted SWAJ who then intervened on Maria's behalf. Maria reported that the officer who arrested her had sex with her on numerous occasions and refused to pay. He warned Maria that if she refused to have sex with him, he would arrest her. A couple of weeks earlier, Maria had been standing on the corner with other sex workers when this same officer pulled up in a private vehicle and asked

\footnotetext{
${ }^{2}$ Name changed to a pseudonym to protect privacy.

${ }^{3}$ Name changed to a pseudonym to protect privacy.

${ }^{4}$ Name changed to a pseudonym to protect privacy.

${ }^{5}$ Name changed to a pseudonym to protect privacy.
} 
her to get in. Maria refused, and when he tried to force her, the other sex workers began arguing and fighting him. He left, promising Maria that he would 'get her'for this. With SWAJ's assistance, Maria was not charged. Yet later that year, Maria was arrested by the same officer and charged for loitering in a public place; she pleaded guilty and was fined and released. At this point Maria began feeling suicidal. She started to engage with SWAJ, and describes this as a turning point in her life. Maria attends legal literacy sessions for sex workers with SWAJ; in these sessions she first heard the phrase "sex workers have rights too". Maria met sex workers who were empowered -they filed police reports, sought justice and advocated for sex workers' human rights.

Maria began receiving psycho-social support from SWAJ via support groups and sessions with a psychologist, and she describes this as what "keeps her going". She shares her experiences of violence and abuse with others at the sex worker support groups at SWAJ, where she has the opportunity to meet others with similar experiences. Maria describes SWAJ as 'her family'. Through her involvement with SWAJ, Maria is more aware of the laws that criminalise sex work. She still lives in fear of losing her two other children to state custody due to the existence of laws that criminalise living off the earnings of prostitution and being habitually in the company of a prostitute, resulting in direct implications for her children. Maria has witnessed many sex workers' children removed to state custody, and having this personal experience herself, she understands the resulting mental health impacts. Recently, Maria described being chastised by a nurse at a public health facility for engaging in sex work. She left the facility without receiving the services she required and returned accompanied by a SWAJ representative. While advocating for her own rights, Maria continues to provide support to, and receive support from, other sex workers.

\section{Findings from a Community-Based Research Study with Sex Workers in Jamaica}

We conducted a community-based research project in collaboration with the SWAJ and Jamaica AIDS Support for Life, with a peer-driven recruitment sample of cisgender men, trans women, and cisgender women sex workers in Kingston, Montego Bay, Ocho Rios, and surrounding areas. We hired and trained sex workers, including trans women, cisgender women, and cisgender men, as peer research assistants. Peer research assistants helped to refine the survey through pilot testing, distributed the study information to their networks, and conducted a tablet-based, cross-sectional survey of 30-40 min in duration to explore social and structural factors associated with health and well-being. Inclusion criteria comprised the following: self-identifying as a sex worker (exchanging sex for money or goods); living in Jamaica, residing in or nearby Kingston, Ocho Rios, and Montego Bay; and being 18 years of age and older. We used multiple convenience sampling methods, including venue-based recruitment through advertising the study via word-of-mouth 
at Jamaica AIDS Support for Life and SWAJ. We also used snowball sampling by notifying participants that they could invite other sex workers in their networks to participate. No print advertisement was used. The study was approved by research ethics boards at the University of Toronto and the University of the West Indies.

\section{Measures}

The primary explanatory variable was sex work social cohesion, using a 14-item sex work social cohesion scale [24] (range: 15-54; Cronbach's alpha $=0.78$ in this study). Examples of items included the following: On a scale of 1 (strongly disagree) to 4 (strongly agree), you can count on your colleagues if you need to:

"borrow money"

"ask someone to accompany you to the doctor or hospital"

"help you deal with a violent or difficult client"

Outcome variables included depressive symptoms, violence from clients and intimate partners, and police harassment/arrest. Depressive symptoms in the last 2 weeks were measured continuously with the two-item Patient Health Questionnaire-2 (PHQ-2) (range 2-8) [25]. Client violence was measured with the item: "Have you experienced violence (verbal, physical or sexual) from a sex work client in the last 6 months?" An affirmative answer was coded as having recent client violence experience. Intimate partner violence was measured with the item: "In your life, have you ever experienced violence from a partner (boyfriend, girlfriend)?" Participants who reported "yes" were coded as having intimate partner violence experience. Police harassment and arrest [11] was assessed by using the following items: "On a scale of 1 (never) to 3 (many times), how often have the police: (1) thrown you in jail/lockup; (2) sexually harassed you (called your names/groped you); (3) beaten you up; (4) robbed you of money or drugs; (5) raped you or bribed you (give a "thing") to keep working; or (6) arrested you/charged you?" Participants who reported having had any of the preceding experiences were coded as having experienced police harassment/arrest. The final value for types of violence/harassment experienced was calculated from the previously mentioned scores for client violence, intimate partner violence, and police harassment/arrest, to produce a score ranging from 0 to 3 types of violence/harassment.

Potential mediators included sex work stigma and binge drinking. Sex work stigma was measured based on a 4-item scale adapted from Lazarus et al.'s "Occupational Sex Work Stigma Scale" [26] (Examples: "Do you hide involvement in sex work from family and friends"; "Do you hide involvement in sex work from your home community"; and "Do you hide involvement in sex work from your doctor or healthcare provider"; and "Do you believe sex work is shameful") (range: 0-8, Cronbach's alpha = 0.71). Binge drinking was measured by: "How many drinks do you usually have per sitting/outing?" Participants who reported having five drinks or more were coded as binge drinking. Socio-demographic characteristics were 
examined as covariates: age (continuous), education level (dichotomous: less than high school vs. high school or higher), and monthly income (continuous).

\section{Statistical Analysis}

We first conducted descriptive analyses of all variables for the whole sample. Bivariate analysis was performed to identify the difference of socio-demographic characteristics by gender (cisgender men, cisgender women, trans women). We conducted an explanatory factor analysis (EFA) and confirmatory factor analysis (CFA) to determine the validity of the latent construct of sex work social cohesion using the social cohesion scale [24], as this measure had not previously been used in the Jamaican context. Structural equation modelling (SEM) using weighted least squares estimation methods was conducted to examine the direct and indirect effect of the latent construct of sex work social cohesion on types of violence/harassment experienced (clients, intimate partners, police) and depressive symptoms, testing the potential mediating effects of sex work stigma and binge drinking. Model fit was assessed using: Chi-square, Root Mean Square Error of Approximation (RMSEA), and Comparative Fit Index (CFI). A significance level for Chi-square of $<0.05$, a score of $<0.05$ for RMSEA with $90 \%$ confidence interval between 0.02 and 0.08 , and a score greater than 0.90 for CFI indicate acceptable model fit. Statistical significance was set at the $p<0.05$ level. Missing responses were excluded from the analyses. All statistical analyses were performed using Stata (version 14.0).

\section{Results}

Table 5.1 reports the socio-demographic characteristics for the whole sample and the differences by gender among 340 sex worker participants (mean age: 25.77, $\mathrm{SD}=5.71$, range: 17-57) across three sites in Jamaica (Kingston, Ocho Rios, Montego Bay). These included 124 (36.47\%) who identified as cisgender men, 101 $(29.71 \%)$ trans women, and $115(33.82 \%)$ cisgender women. Approximately threequarters of the sample $(N=266,78.24 \%)$ had completed high school or higher. The mean weekly income received was USD $119.92(\mathrm{SD}=131.50)$. More than half of the participants $(173 / 338,51.18 \%)$ reported having ever experienced police harassment/arrest (including being locked up, sexually harassed, beaten up, robbed, raped, or arrested by police). More than one-third $(N=116,36.14 \%)$ reported having experienced violence from clients in the last 6 months. Nearly half $(N=167,49.41 \%)$ reported having ever experienced intimate partner violence. Trans women were more likely to report police and client violence than cisgender women and cisgender men, and cisgender women were more likely to report intimate partner violence than trans women or cisgender men. 
Table 5.1 Socio-demographic characteristics among sex workers in Jamaica $(N=340)$

\begin{tabular}{|c|c|c|c|c|c|c|}
\hline Characteristics & $\begin{array}{l}\text { Total } N \\
(\%) / \\
\text { mean } \\
\text { (SD, } \\
\text { range) }\end{array}$ & Missing & $\begin{array}{l}\text { Cisgender } \\
\text { men sex } \\
\text { workers } N \\
(\%) / \text { mean } \\
\text { (SD, range) }\end{array}$ & $\begin{array}{l}\text { Cisgender } \\
\text { women sex } \\
\text { workers } N \\
(\%) / \text { mean } \\
\text { (SD, range) }\end{array}$ & $\begin{array}{l}\text { Transgender } \\
\text { women sex } \\
\text { workers } N \\
(\%) / \text { mean }(\mathrm{SD}, \\
\text { range) }\end{array}$ & $\begin{array}{l}p \\
\text { (ANOVA/ } \\
\text { Chi- } \\
\text { square) }\end{array}$ \\
\hline Total & $N=340$ & & $\begin{array}{l}N=124 \\
(36.47 \%)\end{array}$ & $\begin{array}{l}N=115 \\
(33.82 \%)\end{array}$ & $\begin{array}{l}N=101 \\
(29.71)\end{array}$ & \\
\hline Age & $\begin{array}{l}25.77 \\
(5.71 \\
17-57) \\
\end{array}$ & 13 & $\begin{array}{l}24.72(4.11, \\
17-38)\end{array}$ & $\begin{array}{l}28.07(6.54, \\
17-57)\end{array}$ & $\begin{array}{l}24.57(5.75 \\
17-51)\end{array}$ & $<0.001$ \\
\hline $\begin{array}{l}\text { Weekly income } \\
\text { in USD }\end{array}$ & $\begin{array}{l}119.92 \\
(131.50 \\
0-1580)\end{array}$ & & $\begin{array}{l}95.03 \\
(84.62, \\
0-711)\end{array}$ & $\begin{array}{l}152.64 \\
(166.64, \\
0.079-1580)\end{array}$ & $\begin{array}{l}109.84 \\
(126.72, \\
0.079-790)\end{array}$ & $<0.01$ \\
\hline $\begin{array}{l}\text { Education: } \\
\text { completed high } \\
\text { school or higher }\end{array}$ & $\begin{array}{l}266 \\
(78.24)\end{array}$ & & $106(85.48)$ & $81(70.43)$ & $79(78.22)$ & $<0.05$ \\
\hline City & & & & & & $<0.001$ \\
\hline Kingston & $\begin{array}{l}101 \\
(29.71)\end{array}$ & & $21(16.94)$ & $27(23.48)$ & $53(52.48)$ & \\
\hline Montego Bay & $\begin{array}{l}72 \\
(21.18)\end{array}$ & & $30(24.19)$ & $32(27.83)$ & $10(9.90)$ & \\
\hline Negril & $20(5.88)$ & & $12(9.68)$ & 7 (6.09) & $1(0.99)$ & \\
\hline Spanish Town & $25(7.35)$ & & $5(4.03)$ & $8(6.96)$ & $12(11.88)$ & \\
\hline Ocho Rios & \begin{tabular}{|l|l}
71 \\
$(20.88)$
\end{tabular} & & $34(27.42)$ & $27(23.48)$ & $10(9.90)$ & \\
\hline Others & $\begin{array}{l}51 \\
(15.00)\end{array}$ & & $22(17.74)$ & $14(12.17)$ & $15(14.85)$ & \\
\hline $\begin{array}{l}\text { Relationship } \\
\text { status }\end{array}$ & & 3 & & & & $<0.001$ \\
\hline $\begin{array}{l}\text { Married or } \\
\text { living together }\end{array}$ & $\begin{array}{l}43 \\
(12.76)\end{array}$ & & $13(10.57)$ & $22(19.13)$ & $8(8.08)$ & \\
\hline $\begin{array}{l}\text { Dating-not } \\
\text { living together }\end{array}$ & $\begin{array}{l}58 \\
(17.21)\end{array}$ & & $18(14.63)$ & 17 (14.78) & $23(23.23)$ & \\
\hline Casual dating & $\begin{array}{l}45 \\
(13.35)\end{array}$ & & $24(19.51)$ & $11(9.57)$ & $10(10.10)$ & \\
\hline $\begin{array}{l}\text { No current } \\
\text { partner }\end{array}$ & $\begin{array}{l}96 \\
(28.49)\end{array}$ & & $42(34.15)$ & $32(27.83)$ & $22(22.22)$ & \\
\hline $\begin{array}{l}\text { Multiple } \\
\text { partners/ } \\
\text { polyamorous }\end{array}$ & $\begin{array}{l}95 \\
(28.19)\end{array}$ & & $26(21.14)$ & $33(28.70)$ & $36(36.36)$ & \\
\hline $\begin{array}{l}\text { Police } \\
\text { harassment } \\
\text { (ever) }\end{array}$ & $\begin{array}{l}173 \\
(51.18)\end{array}$ & 2 & $52(41.94)$ & $55(47.83)$ & $66(66.67)$ & $<0.01$ \\
\hline $\begin{array}{l}\text { Intimate partner } \\
\text { violence (ever) }\end{array}$ & $\begin{array}{l}167 \\
(49.41)\end{array}$ & 2 & $51(41.13)$ & $70(60.87)$ & 46 (46.46) & $<0.01$ \\
\hline $\begin{array}{l}\text { Client violence } \\
\text { (past } 6 \text { months) }\end{array}$ & $\begin{array}{l}116 \\
(36.14)\end{array}$ & 19 & $32(27.83)$ & 37 (34.58) & 47 (47.47) & $<0.05$ \\
\hline
\end{tabular}


Table 5.1 (continued)

\begin{tabular}{c|l|l|l|l|l|l}
\hline & $\begin{array}{l}\text { Total } N \\
(\%) / \\
\text { mean } \\
(\mathrm{SD}, \\
\text { range) }\end{array}$ & Missing & $\begin{array}{l}\text { Cisgender } \\
\text { men sex } \\
\text { workers } N \\
(\%) / \text { mean } \\
(\mathrm{SD}, \text { range })\end{array}$ & $\begin{array}{l}\text { Cisgender } \\
\text { women sex } \\
\text { workers } N \\
(\%) / \text { mean } \\
(\mathrm{SD}, \text { range })\end{array}$ & $\begin{array}{l}\text { Transgender } \\
\text { women sex } \\
\text { workers } N \\
(\%) / \text { mean }(\mathrm{SD}, \\
\text { range })\end{array}$ & $\begin{array}{l}p \\
\text { (ANOVA/ } \\
\text { Chi- } \\
\text { square })\end{array}$ \\
\hline Binge drinking & $\begin{array}{l}79 \\
(23.24)\end{array}$ & & $23(18.55)$ & $27(23.48)$ & $29(28.71)$ & 0.199 \\
\hline $\begin{array}{l}\text { Sexual } \\
\text { orientation }\end{array}$ & 18 & & & & $<0.001$ \\
\hline Heterosexual & $\begin{array}{l}119 \\
(36.96)\end{array}$ & & $9(7.83)$ & $80(74.77)$ & $30(30.00)$ & \\
\hline Bisexual & $\begin{array}{l}86 \\
(26.71)\end{array}$ & & $53(46.09)$ & $25(23.36)$ & $8(8.00)$ & \\
\hline Gay/lesbian & $\begin{array}{l}111 \\
(34.47)\end{array}$ & & $51(44.35)$ & $2(1.87)$ & $58(58.00)$ & \\
\hline Queer & $6(1.86)$ & & $2(1.74)$ & 0 & $4(4.00)$ & \\
\hline
\end{tabular}

Table 5.2 Univariate and multivariate linear regressions on depressive symptoms and types of violence among sex workers in Jamaica $(N=340)$

\begin{tabular}{|c|c|c|c|c|}
\hline \multirow[b]{2}{*}{ Variables } & \multicolumn{2}{|c|}{ Depressive symptoms } & \multicolumn{2}{|l|}{ Types of violence } \\
\hline & $\begin{array}{l}\text { Unadjusted } \\
\text { coefficient }(95 \% \\
\mathrm{CI})\end{array}$ & $\begin{array}{l}\text { Adjusted } \\
\text { coefficient }(95 \% \\
\text { CI)* }\end{array}$ & $\begin{array}{l}\text { Unadjusted } \\
\text { coefficient }(95 \% \\
\text { CI) }\end{array}$ & $\begin{array}{l}\text { Adjusted } \\
\text { coefficient }(95 \% \\
\text { CI)* } \\
\end{array}$ \\
\hline $\begin{array}{l}\text { Sex work } \\
\text { social cohesion }\end{array}$ & $\begin{array}{l}-0.05(-0.08 \text { to } \\
\left.-0.03^{* * *}\right)\end{array}$ & $\begin{array}{l}-0.04(-0.07 \text { to } \\
-0.02)\end{array}$ & $\begin{array}{l}-0.04(-0.05 \text { to } \\
-0.03)^{* * *}\end{array}$ & $\begin{array}{l}-0.02(-0.04 \text { to } \\
0.01)^{* *}\end{array}$ \\
\hline $\begin{array}{l}\text { Sex work } \\
\text { stigma }\end{array}$ & $\begin{array}{l}0.12(0.03 \text { to } \\
0.21)^{* *}\end{array}$ & $\begin{array}{l}0.06(-0.04 \text { to } \\
0.15)\end{array}$ & $\begin{array}{l}0.21(0.16 \text { to } \\
0.26)^{* * *}\end{array}$ & $\begin{array}{l}0.17 \text { (0.12 to } \\
0.22)^{* * *}\end{array}$ \\
\hline Binge drinking & $\begin{array}{l}0.75 \text { (0.29 to } \\
1.20)^{* *}\end{array}$ & $\begin{array}{l}0.40(-0.07 \text { to } \\
0.87)\end{array}$ & $0.68(0.40$ to 0.96$)$ & $\begin{array}{l}0.27(-0.01 \text { to } \\
0.54)\end{array}$ \\
\hline
\end{tabular}

Note: $* p<0.05, * * p<0.01, * * * p<0.001$. Covariates include: age, weekly income, education level, relationship status, and gender identity

Table 5.2 displays the results of univariate and multivariate linear regression analysis on depressive symptoms and types of violence among sex workers in Jamaica. We found that, when adjusting for socio-demographic factors (age, income, education, relationship status, gender identity), lower sex work social cohesion was associated with: higher depression symptoms (Acoef: $-0.04,95 \% \mathrm{CI}:-0.07$ to -0.02 ), increased violence and harassment, (Acoef: $-0.02,95 \% \mathrm{CI}:-0.04$ to -0.01 ), and increased sex work stigma (Acoef: 0.17, 95\% CI: 0.12-0.22). Taken together, this suggests that increasing social cohesion among sex workers could reduce depression, risks of violence, and sex work stigma.

The structural equation modelling analyses examined the direct and indirect effects of sex work social cohesion on depressive symptoms and experiences of violence. Final model fit indices suggested that the model fit the data well $\left(\chi^{2}[7]=10.28, p=0.173 ; \mathrm{CFI}=0.983 ; \mathrm{RMSEA}=0.044 ; \mathrm{SRMR}=0.026\right)$. Table 5.3 
Table 5.3 Final path analysis for sex work social cohesion on depressive symptoms and violence among sex workers in Jamaica $(N=340)$

\begin{tabular}{|c|c|c|c|c|}
\hline Parameter & Coefficient (SE) & Critical ratio & $p$ & Standardized estimate \\
\hline \multicolumn{5}{|l|}{ Depressive symptoms ON } \\
\hline Sex work social cohesion & $-0.046(0.013)$ & -3.50 & $<0.001$ & $-0.231(0.065)$ \\
\hline Sex work stigma & $0.045(0.048)$ & 0.96 & 0.339 & $0.649(0.068)$ \\
\hline Binge drinking & $0.370(0.241)$ & 1.53 & 0.125 & $0.101(0.065)$ \\
\hline \multicolumn{5}{|l|}{ Types of violence ON } \\
\hline Sex work social cohesion & $-0.028(0.008)$ & -3.58 & $<0.001$ & $-0.208(0.058)$ \\
\hline Sex work stigma & $0.199(0.028)$ & 7.00 & $<0.001$ & $0.418(0.056)$ \\
\hline Binge drinking & $0.111(0.144)$ & 0.77 & 0.440 & $0.045(0.058)$ \\
\hline \multicolumn{5}{|l|}{ Binge drinking ON } \\
\hline Sex work social cohesion & $-0.007(0.004)$ & -2.00 & $<0.05$ & $-0.132(0.065)$ \\
\hline Sex work stigma & $0.488(0.012)$ & 3.92 & $<0.001$ & $0.256(0.064)$ \\
\hline \multicolumn{5}{|l|}{ Sex work stigma ON } \\
\hline Sex work social cohesion & $-0.094(0.017)$ & -5.46 & $<0.001$ & $-0.333(0.058)$ \\
\hline
\end{tabular}

Covariates include: age, weekly income, education level, relationship status, and gender identity

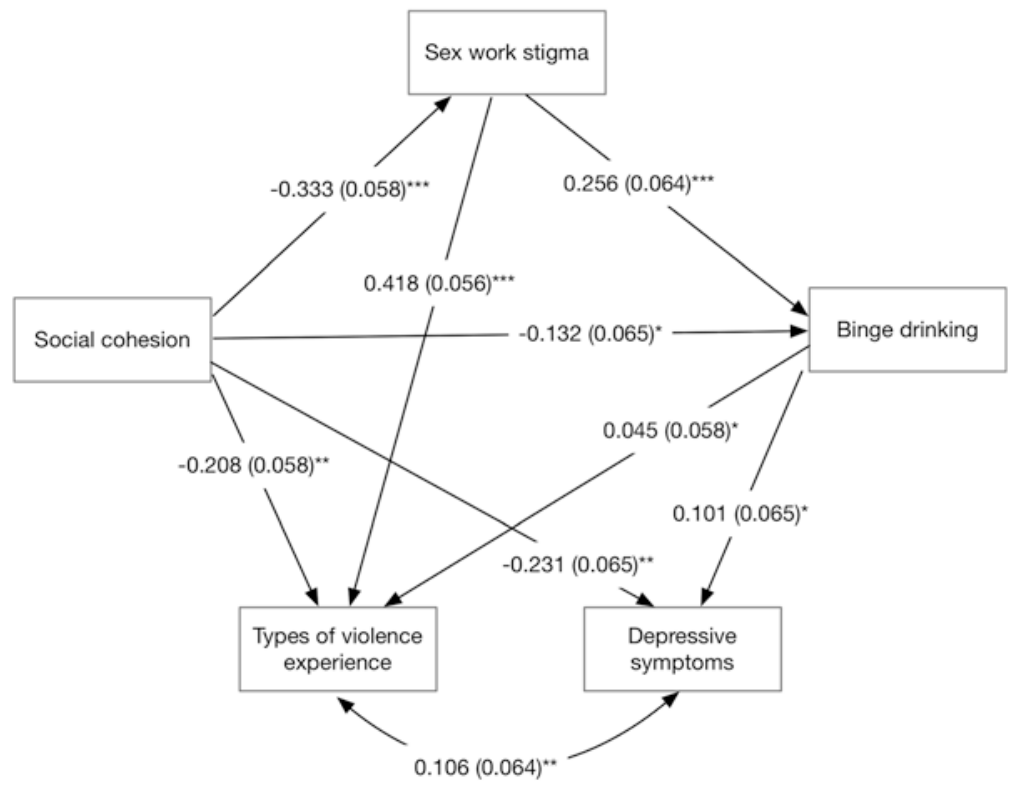

Fig. 5.1 Pathways between sex worker social cohesion, sex work stigma, and depression among sex workers in Jamaica 
displays the results of the final model and Fig. 5.1 illustrates the model with standard coefficients and the significance levels of each pathway. ${ }^{6}$ Standard errors are included in parenthesis. In the final model, sex work social cohesion was associated with fewer depressive symptoms $(\beta=-0.046$ for direct effect, $p<0.001 ;-0.009$ for indirect effect, $p<0.001)$ and less violence $(\beta=-0.028$ for direct effect, $p<0.001$; -0.020 for indirect effect, $p<0.001)$. Sex work stigma partially mediated these relationships: social cohesion among sex workers reduced experiences of sex work stigma; in turn, lower sex work stigma resulted in lower depression and fewer experiences of violence. Sex work social cohesion, therefore, emerged as important to promoting mental health and reducing violence among sex workers in this study.

The case example and community-based study have limitations. First, study authors developed a case study based on in-depth conversations with sex workers at SWAJ. This case study is limited in representing one perspective from a cisgender woman sex worker; generating additional cases with cisgender women, cisgender men, and trans women would provide additional richness of understanding these lived experiences. Second, the experiences of trans men sex workers remain unexplored in this study. Third, the survey was cross-sectional with non-random sampling, limiting the ability to generalise findings or ascertain causality. Finally, we used single items to assess client violence and intimate partner violence.

More detailed measures could have provided information to tailor violence prevention strategies, and would have allowed us to create latent constructs for each type of violence rather than one latent violence construct for combined experiences of violence. Such an approach would allow exploration of pathways between sex work social cohesion and each type of violence. Despite these limitations, this study included over 300 sex workers in Jamaica - a context in which sex work and samegender sexual practices are criminalised. It also provides novel information about the importance of sex work social cohesion and measures to address sex work stigma for better understanding mental health, violence, and harassment among sex workers.

\section{Discussion: Implications for Researchers, Service Providers, and Activists}

This chapter has considered the associations between sex work social cohesion and reduced experiences of violence, harassment, and depression among sex workers in Jamaica. The case study narrative provides insight into the lived experiences of polyvictimisation of a cisgender woman sex worker in Jamaica, and the ways that sex work criminalisation exacerbated her abuse by police and clients while simultaneously

\footnotetext{
${ }^{6}$ The standard coefficient indicated that with a standard deviation of increase of the independent variable, the dependent variable would increase by $x$ standard deviation, holding all other variables constant.
} 
reducing her access to justice. The case study also points to the ways in which stigma targeting sex workers can result in the forced removal of children to child protective services, and the harmful mental health impacts of such violence and loss. Finally, this case study illuminated the ways that sex workers share experiences and provide informal support with one another to build community, as well as the formal rights-based programming that a sex worker collective such as the Sex Work Association of Jamaica can provide to advance human rights and access to health services among sex workers.

The empirical data from a cross-sectional survey in Jamaica corroborated and expanded on the case study by including cisgender men, cisgender women, and trans women sex workers. Findings reveal that trans women sex workers are particularly impacted by police harassment/arrest and client violence, while cisgender women sex workers are disproportionately affected by intimate partner violence. These findings have implications for rights-based programming, gender-tailored support, and violence reduction programmes by and for sex workers. Extending beyond Jamaica, these findings can inform research, service provision, and activism with sex workers in global contexts, particularly where sex work and same-gender sexual practices are criminalised. Sex work social cohesion is a strengths-based construct that shows the powerful role support and care among sex workers have on well-being.

Research Implications Taken together, these findings corroborate prior research that demonstrates the deleterious impacts of sex work criminalisation on the health and human rights of sex workers [7], including violence and harassment from police, clients, and intimate partners [11, 14, 27]. The prevalence of violence reported by sex workers in our study was comparable to that gathered from a global systematic review [7] (which omitted Caribbean studies), in which sex workers reported lifetime physical/sexual violence prevalence of $45-75 \%$ and past year workplace violence prevalence of 32-55\%. Our findings also corroborate prior work with cisgender women sex workers in Jamaica highlighting rape by clients [28]. These findings signal the need for research that includes cisgender and transgender sex workers, assesses and reduces multiple forms of violence (for instance, by police, partners, clients), and applies a strengths-focused approach centering sex work social cohesion.

Future research can also explore the shared and differential needs and experiences among sex workers by intersecting identities such as gender, age, socioeconomic status, and sexual orientation. While we found gender identity differences in experiences across client violence, intimate partner violence, and police harassment/arrest, we were not able to ascertain how support services could be tailored to meet the diverse needs of sex workers. Qualitative studies could provide further understanding of experiences of social cohesion among sex workers and provide their recommendations for rights-based programming.

Service Provision Implications Social cohesion among sex workers emerged as a protective factor associated with reduced sex work stigma, reduced depression, reduced experiences of violence and harassment and, in the case study, increased 
access to health care and legal literacy. This corroborates findings that social support is health-promoting and can reduce barriers when it comes to accessing health care among general populations [20]. Similar to a study in Eswatini (formerly known as Swaziland), we found that sex work social cohesion was associated with reduced odds of experiencing stigma, violence, harassment, and arrest [17]. Findings also contribute to the knowledge base regarding social cohesion among sex workers and their rates of mental health. Similar to findings with non-sex work specific populations [23], we found social cohesion to be associated with reduced depression. Taken together, these findings can contribute to trauma-informed mental health programmes by, with, and for sex workers, that build opportunities and resources for mutual aid, advocacy, and social support. In addition to providing counselling, service providers can offer training and resources to support the development of sex workers' sustainable rights-based and solidarity-oriented programmes and groups.

Implications for Activism Findings point to the urgent need to end sex work criminalisation across global contexts and provide sex workers with legal rights and protections. Similar to prior research in four Sub-Saharan African countries, the case study pointed to fears of reporting violence to police due to punishment, arrest, and further violence [29]. The quantitative data also provided evidence that sex workers in Jamaica experience harassment and arrest by police, as they do in other contexts $[7,11,27]$. Yet sex work social cohesion combined with advocacy and education about legal rights, as described in the case study, has the potential to provide recourse to justice for sex workers. In the quantitative data, sex work social cohesion was also linked with reduced violence, harassment, and arrest, suggesting the importance of community-engaged and rights-based interventions by and for gender-diverse sex workers [30]. Community empowerment approaches must be coupled with changes at a structural level such as (a) the decriminalisation of sex work and same-gender sexual practices, and (b) training and policies to reduce intersectional stigma (towards sex workers and lesbian, gay, bisexual, and transgender persons) among healthcare and social service providers, police, communities, and within intimate partnerships. Such approaches can also advance HIV prevention. A conceptual model with cisgender women sex workers in Jamaica, for example, positions sexual decision-making constraints within the sex work environment of criminalisation [31]. In fact, estimates suggest that the decriminalisation of sex work could prevent $33-46 \%$ of new HIV infections in the next 10 years [11]. Future research could assess the mental health benefits of sex work decriminalisation, and the potential role of sex work social cohesion in decriminalisation efforts and mental health promotion.

This chapter advances understanding of multiple forms of violence experienced by sex workers in Jamaica, and the protective role of sex work social cohesion. It also furthers an intersectional approach $[6,32]$ that points to the importance of considering gender identity in shaping life experiences. Prior research with trans women [15] and gay, bisexual, and other men who have sex with men [12] in Jamaica reported higher levels of stigma and rape among those who were involved in sex work. 
The study detailed in this chapter found different experiences of violence based on gender identity, with a particularly high burden of police harassment and client violence experienced by trans women sex workers in comparison to their cisgender women and men counterparts. This necessitates an intersectional approach with sex workers to violence and stigma reduction strategies that identify gender-specific experiences, needs, and priorities. It also highlights the urgent need for decriminalisation of sex work and same-gender sexual practices in Jamaica to advance health and human rights.

Conflict of Interest and Source of Funding The authors have no conflicts of interest to declare. This research was funded by the Canadian Institutes of Health Research (CIHR) Operating Grant 0000303157; Fund: 495419, Competition 201209. Dr. Logie's efforts were in part supported by an Ontario Ministry of Research and Innovation Early Researcher Award, a Canada Research Chair in Global Health Equity and Social Justice with Marginalized Populations, and the Canada Foundation for Innovation.

\section{References}

1. Benoit C, Jansson SM, Smith M, Flagg J. Prostitution stigma and its effect on the working conditions, personal lives, and health of sex workers. J Sex Res. 2018;55(4-5):457-71.

2. Jiao S, Bungay V. Intersections of stigma, mental health, and sex work: how Canadian men engaged in sex work navigate and resist stigma to protect their mental health. J Sex Res. 2019;56(4-5):641-9.

3. Herek GM, Widaman KF, Capitanio JP. When sex equals AIDS: symbolic stigma and heterosexual adults' inaccurate beliefs about sexual transmission of AIDS. Soc Probl. 2005;52(1):15-37.

4. Zarhin D, Fox N. "Whore stigma" as a transformative experience: altered cognitive expectations among Jewish-Israeli street-based sex workers. Cult Health Sex. 2017;19(10):1078-91.

5. Poteat T, Wirtz AL, Radix A, Borquez A, Silva-Santisteban A, Deutsch MB, et al. HIV risk and preventive interventions in transgender women sex workers. Lancet. 2015;385(9964):274-86.

6. Logie CH, James L, Tharao W, Loutfy MR. HIV, gender, race, sexual orientation, and sex work: a qualitative study of intersectional stigma experienced by HIV-positive women in Ontario, Canada. PLoS Med. 2011;8(11):e1001124.

7. Deering KN, Amin A, Shoveller J, Nesbitt A, Garcia-Moreno C, DuffP, et al. A systematic review of the correlates of violence against sex workers. Am J Public Health. 2014;104(5):e42-54.

8. Carlson CE, Witte SS, Pala AN, Tsai LC, Wainberg M, Aira T. The impact of violence, perceived stigma, and other work-related stressors on depressive symptoms among women engaged in sex work. Glob Soc Welf. 2017;4(2):51-7.

9. NSWP. Global mapping of sex work laws [Internet]. Global Network of Sex Work Projects; 2019 [cited 2020 May 13]. Available from: https://www.nswp.org/sex-work-laws-map.

10. Vanwesenbeeck I. Sex work criminalization is barking up the wrong tree. Arch Sex Behav. 2017;46(6):1631-40.

11. Shannon K, Strathdee SA, Goldenberg SM, Duff P, Mwangi P, Rusakova M, et al. Global epidemiology of HIV among female sex workers: influence of structural determinants. Lancet. 2015;385(9962):55-71.

12. Logie CH, Lacombe-Duncan A, Kenny KS, Levermore K, Jones N, Baral SD, et al. Socialecological factors associated with selling sex among men who have sex with men in Jamaica: results from a cross-sectional tablet-based survey. Glob Health Action. 2018;11(1):1424614. 
13. Hail-Jares K, Chang RCF, Choi S, Zheng H, He N, Huang ZJ. Intimate-partner and clientinitiated violence among female street-based sex workers in China: does a support network help? PLoS One. 2015;10(9):e0139161.

14. Shahmanesh M, Wayal S, Cowan F, Mabey D, Copas A, Patel V. Suicidal behavior among female sex workers in Goa, India: the silent epidemic. Am J Public Health. 2009;99(7):1239-46.

15. Logie CH, Wang Y, Lacombe-Duncan A, Jones N, Ahmed U, Levermore K, et al. Factors associated with sex work involvement among transgender women in Jamaica: a cross-sectional study. J Int AIDS Soc. 2017;20(1):21422.

16. Argento E, Duff P, Bingham B, Chapman J, Nguyen P, Strathdee SA, et al. Social cohesion among sex workers and client condom refusal in a Canadian setting: implications for structural and community-led interventions. AIDS and Behavior. 2016;20(6):1275-83.

17. Fonner VA, Kerrigan D, Mnisi Z, Ketende S, Kennedy CE, Baral S. Social cohesion, social participation, and HIV related risk among female sex workers in Swaziland. PLoS One. 2014;9(1):e87527.

18. Jana S, Basu I, Rotheram-Borus MJ, Newman PA. The Sonagachi project: a sustainable community intervention program. AIDS Educ Prev. 2004;16(5):405-14.

19. Langer A, Stewart F, Smedts K, Demarest L. Conceptualising and measuring social cohesion in Africa: towards a perceptions-based index. Soc Indic Res. 2017;131(1):321-43.

20. Chuang Y-C, Chuang K-Y, Yang T-H. Social cohesion matters in health. Int J Equity Health. 2013;12:87.

21. Hong Y, Xiaoyi F, Xiaoming L, Liu Y, Li M, Tai-Seale T. Self-perceived stigma, depressive symptoms, and suicidal behaviors among female sex workers in China. J Transcult Nurs. 2009;21(1):29-34.

22. Jen MH, Sund ER, Johnston R, Jones K. Trustful societies, trustful individuals, and health: an analysis of self-rated health and social trust using the World Value Survey. Health Place. 2010;16(5):1022-9.

23. Fone D, White J, Farewell D, Kelly M, John G, Lloyd K, et al. Effect of neighbourhood deprivation and social cohesion on mental health inequality: a multilevel population-based longitudinal study. Psychol Med. 2014;44(11):2449-60.

24. Lippman SA, Donini A, Díaz J, Chinaglia M, Reingold A, Kerrigan D. Social-environmental factors and protective sexual behavior among sex workers: the Encontros intervention in Brazil. Am J Public Health. 2010;100(Suppl 1):S216-23.

25. Kroenke K, Spitzer RL, Williams JBW. The Patient Health Questionnaire-2: validity of a twoitem depression screener. Med Care. 2003;41(11):1284-92.

26. Lazarus L, Deering KN, Nabess R, Gibson K, Tyndall MW, Shannon K. Occupational stigma as a primary barrier to health care for street-based sex workers in Canada. Cult Health Sex. 2012;14(2):139-50.

27. Beattie TS, Bhattacharjee P, Ramesh B, Gurnani V, Anthony J, Isac S, et al. Violence against female sex workers in Karnataka state, south India: impact on health, and reductions in violence following an intervention program. BMC Public Health. 2010;10:476.

28. Eldemire-Shearer D, Bailey A. Determinants of risk behaviour of sex-workers in Jamaica. A qualitative approach. West Indian Med J. 2008;57(5):450-5.

29. Scorgie F, Vasey K, Harper E, Richter M, Nare P, Maseko S, et al. Human rights abuses and collective resilience among sex workers in four African countries: a qualitative study. Glob Health. 2013;9(1):33.

30. Logie CH, Lacombe-Duncan A, Kenny KS, Levermore K, Jones N, Marshall A, et al. Associations between police harassment and HIV vulnerabilities among men who have sex with men and transgender women in Jamaica. Health Hum Rights. 2017;19(2):147-54.

31. Bailey A, Figueroa JP. A framework for sexual decision-making among female sex workers in Jamaica. Arch Sex Behav. 2016;45(4):911-21.

32. Turan JM, Elafros MA, Logie CH, Banik S, Turan B, Crockett KB, et al. Challenges and opportunities in examining and addressing intersectional stigma and health. BMC Med. 2019;17(1):7. 
Open Access This chapter is licensed under the terms of the Creative Commons Attribution 4.0 International License (http://creativecommons.org/licenses/by/4.0/), which permits use, sharing, adaptation, distribution and reproduction in any medium or format, as long as you give appropriate credit to the original author(s) and the source, provide a link to the Creative Commons license and indicate if changes were made.

The images or other third party material in this chapter are included in the chapter's Creative Commons license, unless indicated otherwise in a credit line to the material. If material is not included in the chapter's Creative Commons license and your intended use is not permitted by statutory regulation or exceeds the permitted use, you will need to obtain permission directly from the copyright holder. 